\title{
Underground Land Administration from 2D to 3D: Critical Challenges and Future Research Directions
}

\author{
Bahram Saeidian*, Abbas Rajabifard (D), Behnam Atazadeh (D) and Mohsen Kalantari \\ The Centre for Spatial Data Infrastructures and Land Administration, Department of Infrastructure Engineering, \\ The University of Melbourne, Melbourne 3010, Australia; abbas.r@unimelb.edu.au (A.R.); \\ behnam.atazadeh@unimelb.edu.au (B.A.); mohsen.kalantari@unimelb.edu.au (M.K.) \\ * Correspondence: bsaeidian@student.unimelb.edu.au
}

Citation: Saeidian, B.; Rajabifard, A.; Atazadeh, B.; Kalantari, M.

Underground Land Administration from 2D to 3D: Critical Challenges and Future Research Directions. Land 2021, 10, 1101. https://doi.org/ 10.3390/land 10101101

Academic Editor: Jenny Paulsson

Received: 3 September 2021

Accepted: 9 October 2021

Published: 17 October 2021

Publisher's Note: MDPI stays neutral with regard to jurisdictional claims in published maps and institutional affiliations.

Copyright: (C) 2021 by the authors. Licensee MDPI, Basel, Switzerland. This article is an open access article distributed under the terms and conditions of the Creative Commons Attribution (CC BY) license (https:// creativecommons.org/licenses/by/ $4.0 /)$.

\begin{abstract}
The development and use of underground space is a necessity for most cities in response to rapid urbanisation. Effective underground land administration is critical for sustainable urban development. From a land administration perspective, the ownership extent of underground assets is essential for planning and managing underground areas. In some jurisdictions, physical structures (e.g., walls, ceilings, and utilities) are also necessary to delineate the ownership extent of underground assets. The current practice of underground land administration focuses on the ownership of underground space and mostly relies on 2D survey plans. This inefficient and fragmented 2D-based underground data management and communication results in several issues including boundary disputes, underground strikes, delays and disruptions in projects, economic losses, and urban planning issues. This study provides a review of underground land administration from three common aspects: legal, institutional, and technical. A range of important challenges have been identified based on the current research and practice. To address these challenges, the authors of this study propose a new framework for 3D underground land administration. The proposed framework outlines the future research directions to upgrade underground land administration using integrated 3D digital approaches.
\end{abstract}

Keywords: underground space; 3D land administration; 3D cadastre; aspects of ULA; subsurface space management

\section{Introduction}

In recent decades, underground areas have been significantly utilised and developed in urban environments. They comprise one of the top ten fronts in civil, hydraulic, and architecture engineering development [1]. Von der Tann, Sterling [2] presented the evolution of underground space uses and needs, as well as reviewing its numerous applications in urban planning in different countries. Currently, underground space is used for establishing many essential infrastructure facilities such as transportation, subways, shopping malls, walkways, utility networks (e.g., electricity, gas, water supply, sewage, drainage, and communication cables), and parking spaces. A significant number of utilities and service networks are located underground. For example, in Australia, it is estimated that there is $740,000 \mathrm{~km}$ of underground infrastructure, which is valued at more than $\$ 340$ billion [3]. In Tokyo, Japan, it is estimated that nearly $99.9 \%$ of the existing buildings have underground basements [4].

As the development and use of underground space increase, it is paramount to have a clear and accurate definition of ownership rights associated with underground assets. The reliable and complete representation of legal spaces can prevent unnecessary costs, delays, and disruptions in many projects [5]. For example, in Malaysia's MRT project, a dispute arose as the surface landowners claimed their rights towards the ownership of underground areas beneath their land parcels [6]. On the other hand, in some jurisdictions, physical structures such as walls, ceilings, and utilities play pivotal roles in defining the 
ownership extent of underground assets. They can also facilitate the communication of legal objects.

In current practices, 2D survey plans are commonly used for registering and managing the ownership extent of underground assets. In these plans, cross-section and isometric diagrams provide height information, which is required to represent the vertical dimensions of underground ownership spaces. Figure 1a shows 2D cross-sectional diagrams for an underground car park with upper and lower limits in Victoria, Australia. Two-dimensional plans are potentially ambiguous in terms of the visualisation and interpretation of 3D ownership extent of underground assets. For example, easements in 2D plans are used to define the legal extent of utilities such as sewerage, drainage, and powerlines [7]. Figure $1 \mathrm{~b}$ shows some intersecting easements in a subdivision plan registered in Victoria. In this way, parcels above the underground assets are known but the physical elements are not registered. The depths of underground objects are not also specified. This type of representation makes it challenging to understand the legal ownership of assets associated with these easements. It is also almost impossible to query utilities themselves because they do not have cadastral identity [8]. Moreover, for each parcel crossed by a pipeline, a reference is created to the same subject (pipeline owner), thus creating a redundancy [9]. Figure 1c shows a plan for an underground tunnel in Victoria. This plan is also 2D, and there is no link to the physical data including geometric and semantic information about physical structures. On the other hand, 2D maps for underground assets' owners only represent the physical extent of these assets (Figure 1d). In most cases, it is difficult to know which land parcels are affected by underground assets such as utility networks since no related information exists from the registration process [10] and there is no link between the physical data and the land parcels and underground ownership spaces.

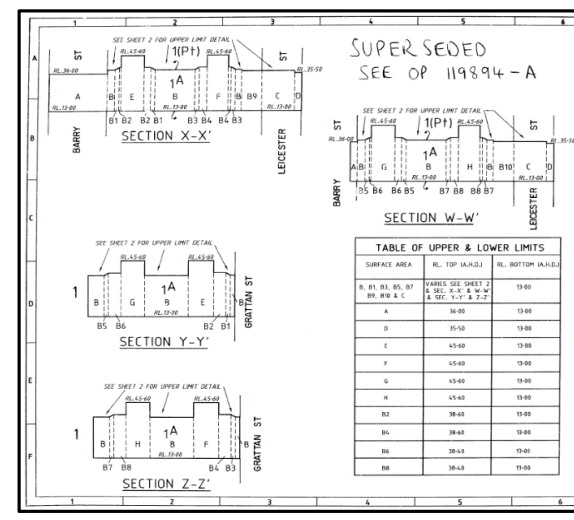

(a)

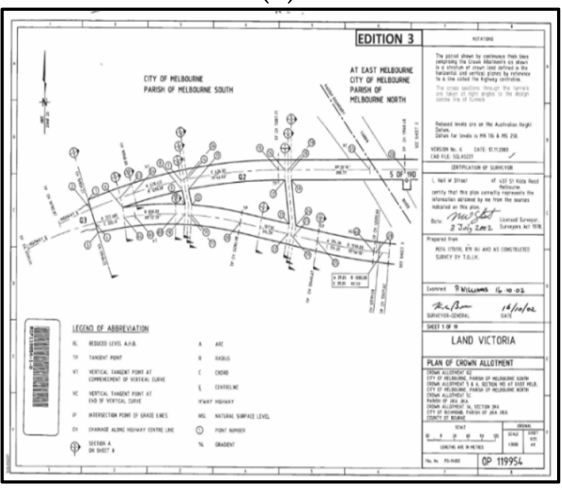

(c)

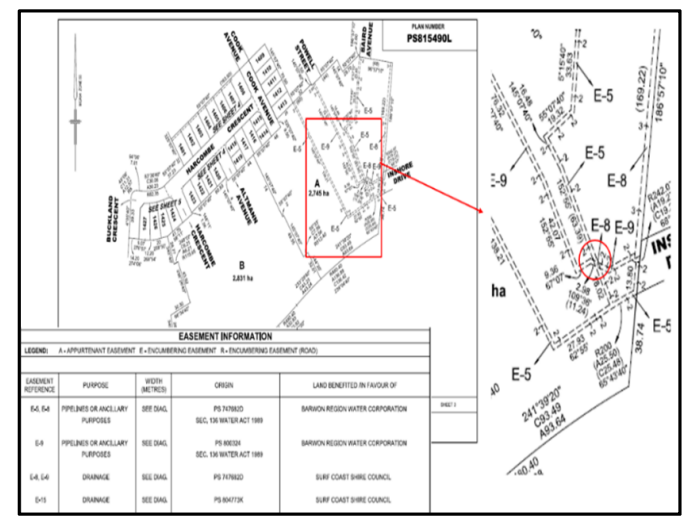

(b)

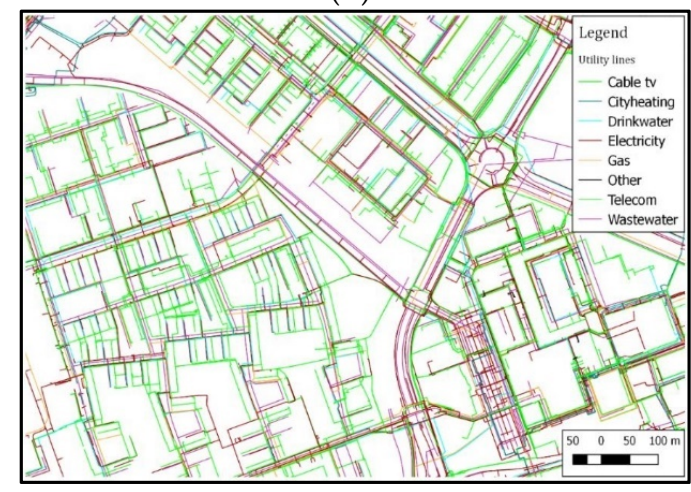

(d)

Figure 1. Current practices for managing legal and physical data of underground assets: (a) 2D cross-sectional diagrams for an underground car park with upper and lower limits, (b) easements as the ownership extent of underground utility networks in a subdivision plan, (c) a plan for an underground tunnel (plans source: [11]), and (d) a sample of utility data in a 2D environment without legal information, adapted with permission from ref. [12], Elsevier. 
The current abovementioned 2D challenges clearly highlight the need to develop an integrated 3D approach for underground land administration. A 3D digital environment can provide a communicable method of managing the ownership extent of underground assets. The integration of legal and physical data in a 3D environment can facilitate the communication of underground ownership spaces (Figure 2). Three-dimensional digital underground models can help answer various spatially complex questions related to ownership and physical dimensions of underground areas, e.g., regarding where the underground infrastructure is located, who the owner is, what kinds of spatial and legal relationships exist between different underground objects, and what the relationships between the underground and aboveground areas are [13,14].

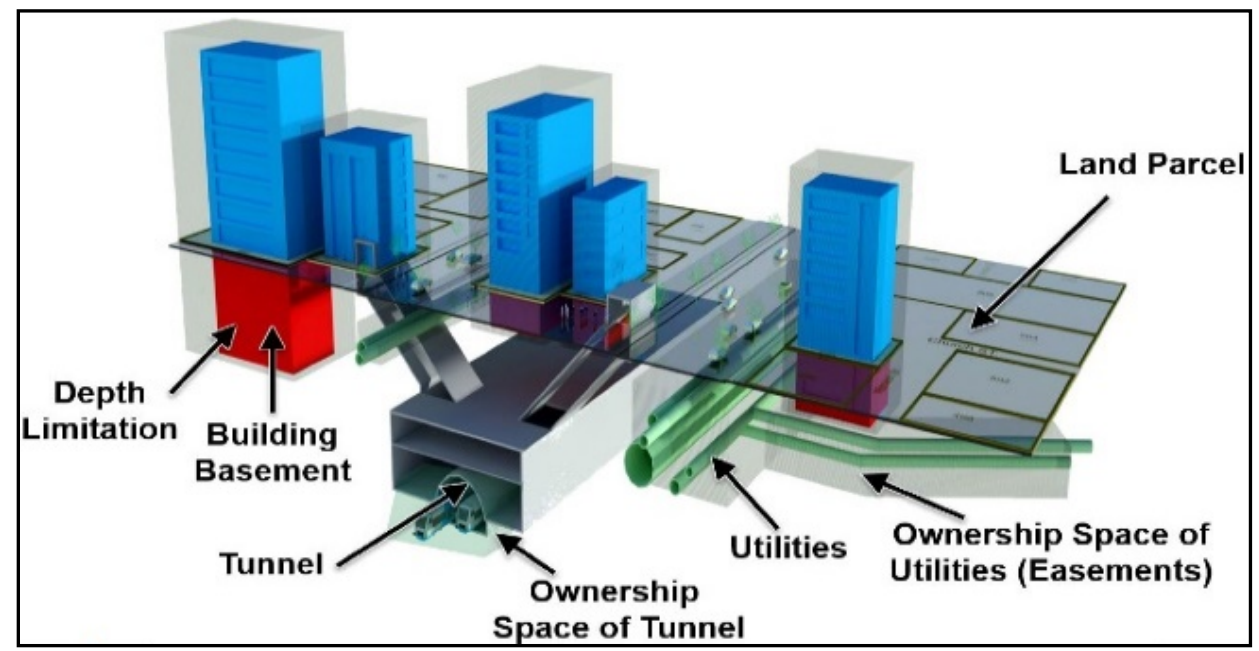

Figure 2. A 3D underground model integrating physical and legal data as an appropriate solution for underground land administration.

To move towards 3D ULA, different legal, institutional, and technical aspects need to be considered. Underground space has specific characteristics and needs particular concerns, e.g., special data acquisition and validation techniques; specific laws and regulations; the complex geometry and topology of various underground assets such as tunnels, utility networks, and train stations; and special visualisation concerns. Therefore, these concerns and issues need to be reviewed and discussed, and the challenges and gaps in current research and practice in this area need to be identified.

This study is intended to provide a review of underground land administration from three common aspects: legal, institutional, and technical. A range of significantly important challenges have been identified in the current research and practice. To address these challenges, the authors of this study propose a new framework for 3D underground land administration. The proposed framework helps us to outline the future research directions to address fundamentally important problems in upgrading underground land administration into a fully integrated 3D digital environment.

\section{Underground Land Administration}

In the modern world, 'land' refers not only to the earth's surface but also any asset located below and above the ground. Underground land information is required for underground space, which is defined as geospace located beneath ground level [15]. It is also known as subsurface space and subterranean space. Underground space contains everything between the ground surface and the core of the earth [4].

The establishment of land administration for underground areas has been identified by some researchers [16-20]. However, there is no agreed upon definition of underground land administration. By considering the generic definition of land administration [21-23], we define underground land administration (ULA) as the information and processes required 
for subdividing, registering, and managing ownership boundaries and rights, restrictions, and responsibilities (RRRs) associated with underground assets.

Due to the increasing development and use of underground space, ULA will play a vital role in the future of cities. For example, according to Cadastre 2034 [24], in Australia in 2034, land administration systems will be playing a significant role in traditional utility systems that are mostly located underground. ULA is necessary for various applications such as the management of utility networks, logistics, military and defence, smart cities, construction projects, emergency response, transportation, excavations, and disaster management. It should include the integration and management of 3D physical and ownership data. To do this, a comprehensive investigation of the different aspects of ULA must be conducted.

There are three aspects of a land administration system: legal, institutional (administrative), and technical $[25,26]$. ULA is a part of land administration and should consider these three aspects. In some studies, these aspects have been presented for underground cadastres $[17,18]$. Therefore, the authors of this research considered and investigated these three aspects of underground land administration.

\subsection{Legal Aspects}

The development of a ULA system should be in compliance with the related regulations and legislation that form the basis for legal aspects. In other words, the legal aspects of ULA specify legislation related to underground ownership RRRs. More broadly, the legal aspects comprise the definition of legal objects, RRRs (e.g., right of superficies and easements), co-ownership, legal notice to reveal the overlapping area of assets legal space, subdivision, and legal framework [10,25-27]. The legislation lays the foundation for realising 3D ULA. Therefore, forming a 3D ULA system is impossible without proper legislation [27]. Appropriate legislation can help to prevent boundary disputes and clarify the real extent of ownership RRRs in underground environments (Figure 3).

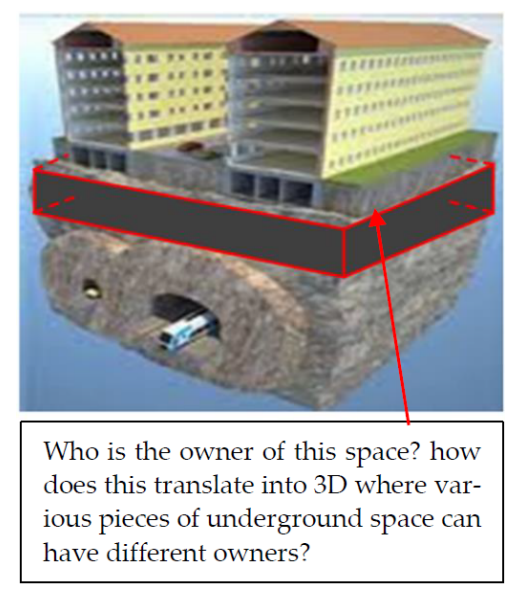

(a)

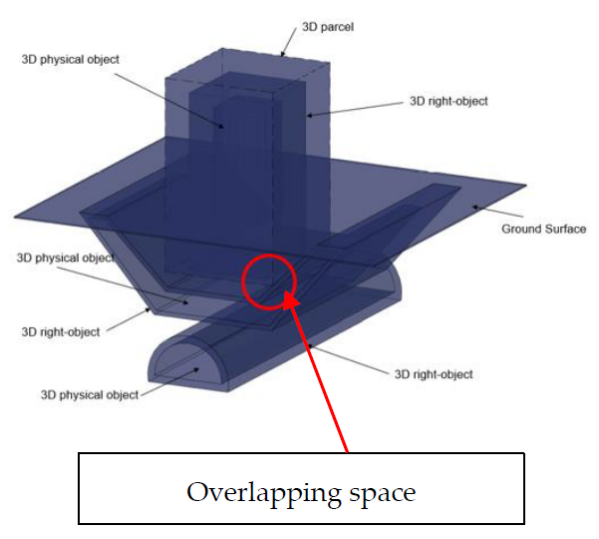

(b)

Figure 3. Some examples showing the importance of proper legislation for (a) defining the ownership of underground areas in 3D (Image source: [28]) and (b) revealing the overlapping space of the ownership extent of underground assets and preventing boundary disputes.

Current legislation is mostly relevant to the ground surface; they have some limitations for registering and managing underground spaces [18,29-31]. There are still some challenges that should be addressed to modernise ULA [4]. Therefore, it is important to investigate the legislation and regulations concerning both underground land ownership and associated RRRs. 


\subsection{Institutional Aspects}

The execution of a new solution for ULA requires a comprehensive understanding of different institutional matters, such as in what ways, according to what processes, and by what financial means the solution should be developed [32]. Therefore, institutional aspects are also important when developing an integrated 3D approach for ULA.

Institutional aspects are necessary for a ULA system to define the tasks and responsibilities of different private/public registration administration sectors. This system should cover the execution and protection of different legislation. The identification of related institutions, user identification, political and public demand, financial and operational issues, interoperability, data sharing, data security, standards, concepts, terminology and semantics used by organisations, and workflow for registering underground objects are important for developing a suitable institutional setting [25-27].

Identifying the key stakeholders in underground land administration is critically important in addressing institutional matters. Several private and public sectors have key roles in a ULA system, depending on different business and administrative processes, as well as private and governmental organisations in different jurisdictions. The identification of stakeholders requires a comprehensive study in each jurisdiction by considering use cases of 3D ULA. For example, the KLIP project in Flanders, Belgium identified the following stakeholders for underground utility management [33]:

1. The utility network authorities in the role of data providers.

2. The construction sector and engineering agencies in the role of consumers.

3. Geographical IT service and software providers.

The stakeholders of an integrated 3D ULA that covers both the legal and physical aspects of underground assets need to be identified in each jurisdiction. Figure 4 shows critical private and public stakeholders involved in underground land administration. Institutional aspects need to establish the relationship between involved parties and define an administrative framework.

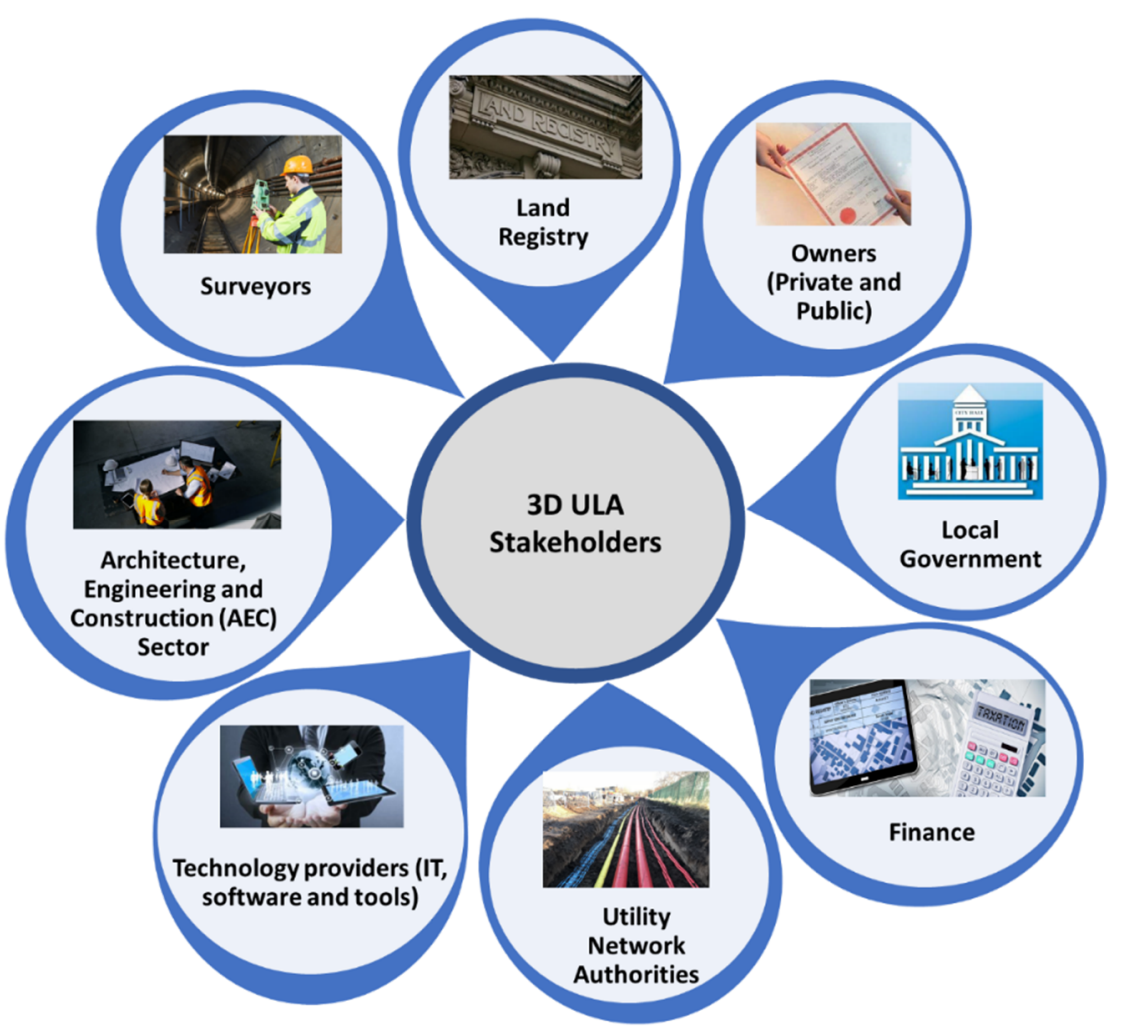

Figure 4. The important stakeholders involved in a ULA system. 


\subsection{Technical Aspects}

Technical aspects refer to the selection of suitable digital technologies for a ULA system. The technical aspects of the utilisation and knowledge of different methods, models, and tools for developing and implementing a 3D land administration system, which could arguably be used and extended for 3D ULA systems, have been investigated in the literature $[25,26,34-38]$.

In many studies, 3D data acquisition, 3D data storage and management, 3D data visualisation, and 3D data dissemination are listed as technical steps/activities for realising a $3 \mathrm{D}$ land administration system $[25,39]$. Most of these efforts have focused on implementing $3 \mathrm{D}$ aboveground land administration systems, so the proposed 3D digital solutions have not been well-developed to support ULA [18].

\section{Current Challenges in ULA}

\subsection{Legal Challenges}

Zaini, Hussin [30] introduced four legal concerns that need to be considered for the underground: the ownership of underground space, a set of rights, depth, and underground space utilisation. Restrictions and responsibilities are also critical in underground spaces. The legal aspects of underground environments depend on the law and legislation in each jurisdiction. To investigate these aspects, current law and practices in each jurisdiction need to be studied.

The ownership of underground space is either an extension of the surface landowner's ownership or separate underground space ownership by a stratum title [30]. Legislation for underground assets can be significantly different from surface infrastructure [40]. In other words, subsurface rights can be independent from surface rights, and the ownership of underground space can be identified as a separate property unit $[4,41]$. This means that underground land below the same parcel can be owned by different owners/actors at different depths [4]. Barker [42] noted that it is possible to legally separate underground land ownership from its surface parcel. For example, it is common to separate the ownership of minerals from surface ownership. It is also challenging to specify the geometric definitions of underground fluid and mineral resources based on surface land ownership [42].

On the other hand, the vertical coexistence of various underground assets associated with different real rights modifies the traditional definition of property rights [43]. The number of tunnels, underground networks, and infrastructure that are not owned by the landowner is increasing [44]. Therefore, specific laws and regulations should be established for special and complex underground space use functions, such as regulations of subsurface utility tunnels and underground complexes [45].

In some investigations, legal issues of underground space and the ownership of this space in different countries and jurisdictions have been studied [13,18,30,42,43,45-51]. Most of these studies concluded that underground property rights are not adequately stabilising public and private interests in the underground. In most jurisdictions, the legislative contents are scattered and incomplete. Legal terms regarding underground ownership and the rights of underground properties are not clear and determinate [45]. This legal ambiguity and unclear ownership are the main issues for underground space development $[4,30,52]$. Surface boundaries are clearly defined for alienated land, but underground land often does not have clearly defined boundaries [31]. In most legislation, there is no restriction on the expansion of property below the ground [27]. However, restrictions are needed to enforce owners for using and maintaining underground assets. Ignoring such infrastructure can create problems [43]. These issues can be resolved if legislation clarifies the ownership of underground space and the extent of disposing of it by an owner [4].

Most regulations for ULA are based on 2D environments and are not capable of supporting 3D digital models. In most jurisdictions, there is a lack of legislative frameworks to mandate the 3D registration of underground properties [53]. Even underground utilities are not recorded in 2D cadastral maps, so land registries rarely register the legal ownership 
of underground utilities [43]. In order to implement a modern ULA system, it is critical to address legal barriers [4]. In the case of the alienation of underground space and the extension of ownership, depth limitation plays a significant role [30]. Different jurisdictions apply four main conditions with regard to underground ownership [4,42]: 1 . the landowner owns the depth (to the centre of the earth); 2. the landowner owns as far as a "reasonably necessary" interest exists; 3 . the landowner owns to a fixed depth limitation ("bounded 3D legal objects" (closed 3D objects) [54]); 4. the parcel does not have private land ownership, so the underground space is publicly owned. There are no solid standards or regulations for "reasonably necessary" interest [18]. It is necessary to study and standardise these definitions in each jurisdiction. Additionally, establishing a fixed depth limitation can lead to some problems as the underground space condition depends on different geotechnical conditions (such as soft clay and hard rock) and land use purposes (e.g., high-rise or low-rise buildings) [4].

Restrictions and responsibilities in underground space should be specified in land titles. For example, a buffer zone of soils and rocks need to be reserved to maintain the force and displacement equilibrium of underground construction [4]. It is also necessary to consider protective areas of utilities based on regulations. In general, underground construction requires buffer zones to maintain the force equilibrium [4]. Tunnel protection and deep underground spaces are other aspects that need to be investigated [46,55]. It is necessary to consider these aspects as restrictions and responsibilities in underground space.

Underground data such as utility network data are often recorded, stored, and managed by their owners. However, their documentation needs to be adapted to the legal administrative process in order to protect people and secure real estate RRRs. Registering underground networks in one unique land register system makes the registration procedure more coherent and consistent [10]. However, in most countries, underground assets, especially utilities, are not displayed on cadastral plans and no public and up-to-date data exist [43]. In other words, cadastral representation (2D/3D) or other information on land parcel restrictions are not mostly available when legal objects are in the underground space [56]. For example, as seen in Figure 5a,b, a sewerage network owned by Melbourne Water Corporation, Victoria, Australia is located under some private properties in Victoria, Australia. However, for the space occupied by the sewerage network, there is no legal information such as easement in the 2D plans [57,58] (Figure 5c). As a secondary legal interest in the Victorian land registry system, some of these parcels (Figure $5 d$ ) do not have depth limitations [5], which could cause disputes for the space occupied by the sewerage network.

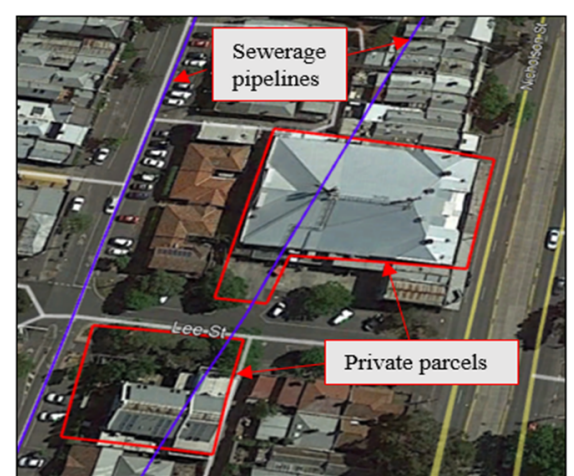

a

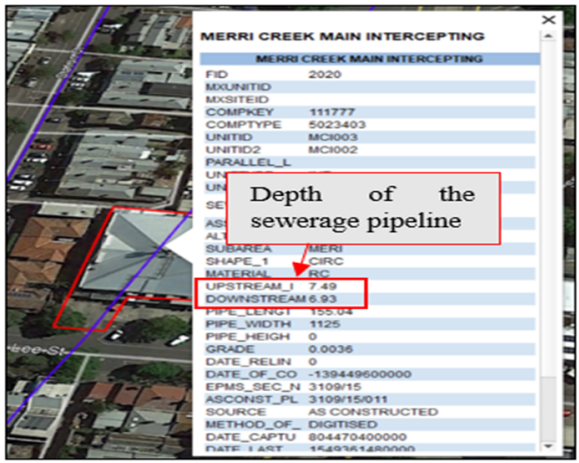

b

Figure 5. Cont. 


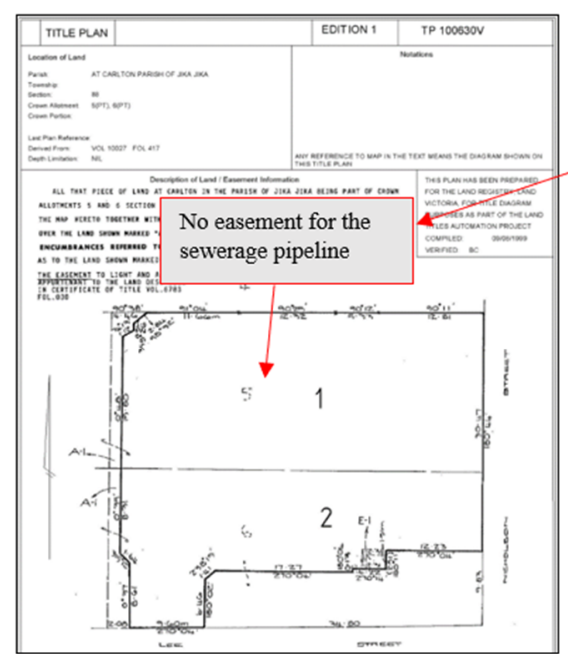

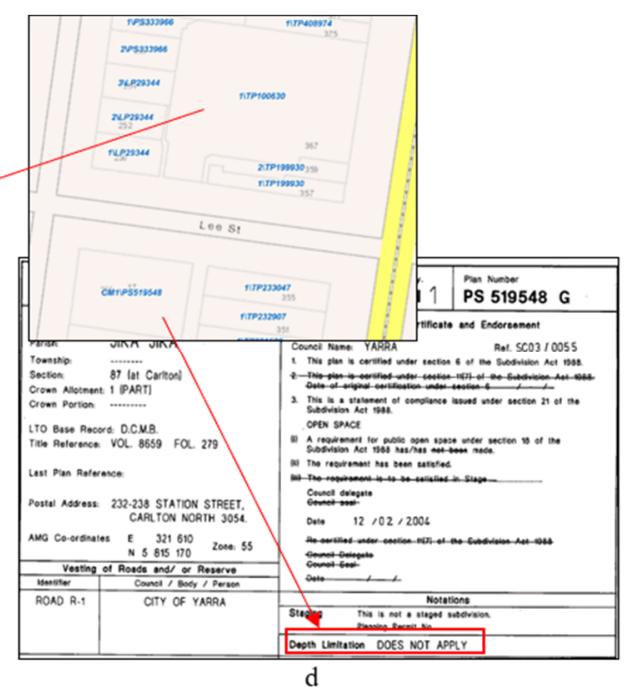

Figure 5. A sewerage network owned by Melbourne Water Corporation located under some private properties in Victoria, Australia: (a) pipeline location (sewerage data source: [59]); (b) pipeline depth; and (c,d) subdivision plans of two parcels above the pipeline assets (subdivision plans source: [11]).

As such, we can identify the following research questions as critical in terms of the legal aspects of ULA:

1. How efficient and effective the current legislation is for registering underground assets and the RRRs associated with them?

2. Does the current legislation support the 3D digital registration of underground assets?

3. What are the required changes/modifications to the current legislation to enable the use of 3D digital underground physical and legal data?

4. Which underground assets should be registered in 3D?

\subsection{Institutional Challenges}

An administrative framework is needed before developing and using underground construction [42]. However, there is a lack of a well-established institutional arrangement to support underground land administration. Additionally, there is no management framework for surveying and registering subsurface assets. The responsibility of involved departments and agencies for the coordinated and integrated administration of underground space in the land administration system is unclear $[18,45]$.

Although collaboration across stakeholders has several benefits in the underground land administration domain (such as enabling new ways of data harmonisation and use; improving the efficiency of design and data acquisition; minimising inconsistencies and data loss, mismatch, and duplication; and enhancing data reuse in different phases [25]), there is a reluctance to share data among many underground asset owners due to commercial sensitivity, competing policies, and security concerns $[4,60]$.

The fundamental role of a registration system is to protect land rights and secure real estate transactions $[10,43]$. Underground assets are also parts of these properties and need to be recorded [10]. However, who is responsible for registering underground assets such as utilities remains unclear. Some studies have noted that these assets should be registered in a land administration system and need to be accessible for those concerned [8,10,20,43,61,62]. A few researchers and jurisdictions have recently started to consider cadastres for underground infrastructures [20]. Figure 6 shows some of them that rely on 2D parcels. 


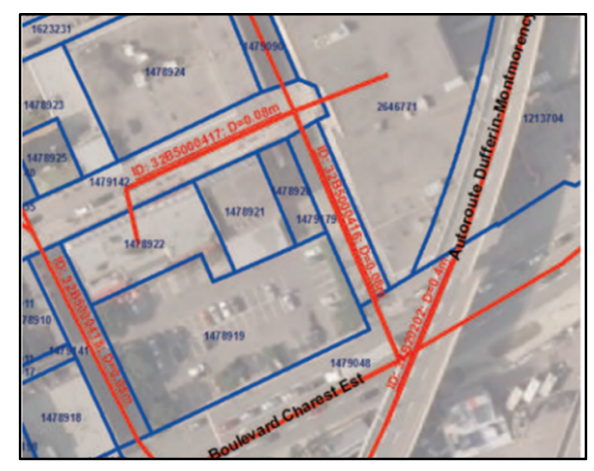

(a)

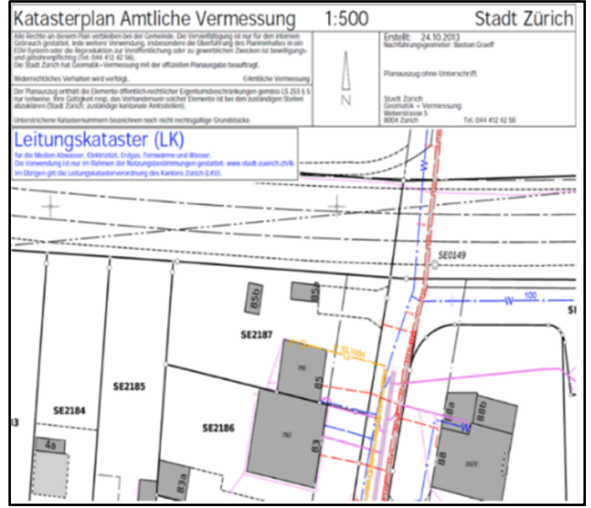

(c)

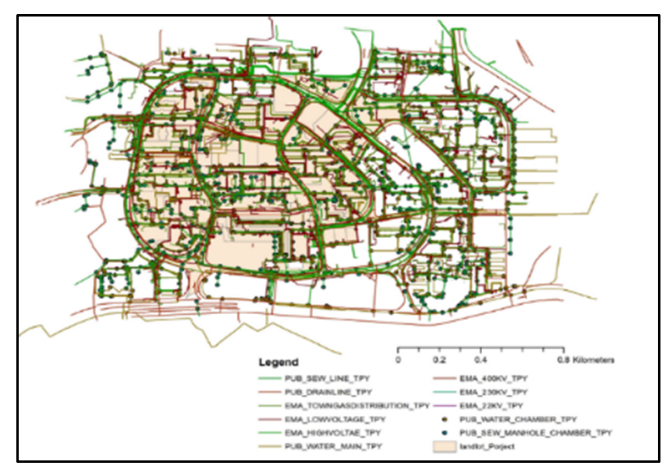

(b)

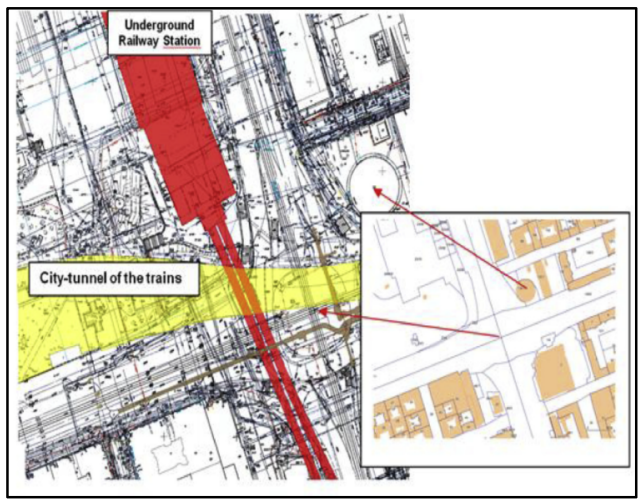

(d)

Figure 6. Some works on registering underground assets: (a) underground communication cables and 2D land parcels, Canada [10]; (b) utility networks and 2D land parcels, Singapore [62]; (c) utility cadastre, Switzerland [61]; and (d) subway data on a cadastral and base map, Poland, adapted with permission from ref. [63], Elsevier.

Some key research questions for institutional aspects of ULA are:

1. Who are the stakeholders of underground land administration?

2. What are the use cases of an integrated 3D ULA system?

3. What are the roles, responsibilities, tasks, and requirements of the involved parties?

4. How can 3D digital models be incorporated into the current workflows for subdividing, registering, and managing underground assets?

5. How can the involved parties be coordinated according to their specific policies, processes, and security and data sharing concerns?

\subsection{Technical Challenges}

Underground assets often have complex geometries that cannot easily be represented or integrated with the current 2D practices [43]. The geometry and topology of subsurface assets can be different from those of land parcels [10]. For example, underground utilities are often very long and cross several parcels or other underground utilities. Modelling utility networks under continuous space specification can be difficult due to possible gaps [10]. Therefore, the technical steps to move from 2D towards 3D ULA can be challenging.

Underground land data can be classified into two categories: physical and legal data. Physical data include the geometric and semantic aspects of physical structures (utilities, walls, ceils, etc.) in underground environments, while legal data refer to ownership attributes and geometric and semantic aspects of underground ownership spaces [64,65]. There are different underground legal and physical elements that lead to complexities in modelling underground space, including different depth limitations, deep underground spaces, accessibilities to underground areas (in some countries, entrances to underground train stations are registered separately), legal and physical lighting data, air exhaust, and 
the ventilation of underground infrastructure, parcels under roads, transportation and utility tunnels, underground mineral resources, and heritages.

Data models play underpinning roles in integrating physical and legal data and managing underground space. Several studies have focused on modelling aboveground assets; however, underground objects are often neglected [66]. On the other hand, current data models focus on the physical or legal aspects of underground space and are mostly based on 2D approaches. The prominent legal 3D model adopted for land administration is the Land Administration Domain Model (LADM) [67]. Some studies have adopted LADM for managing underground land information $[16,17,20,52,62,68,69]$; however, LADM is limited to modelling the ownership space of different underground assets such as utility networks. The primary issue with LADM is its inefficient communication of ownership boundaries referencing physical location of underground assets. For instance, if the ownership boundaries of an easement (e.g., sewerage) are defined below a complex building, a purely legal representation would not be adequate to visually communicate the location of underground boundaries for non-technical stakeholders. Physical 3D data models define the physical reality of subsurface assets (such as tunnels and utilities) in an underground environment. There are two prominent physical models with underground elements: the CityGML [70], used by the spatial and surveying industry, and Industry Foundation Classes (IFC), widely adopted by the architecture and construction industries [71]. Physical 3D data models are currently being used for different applications; however, in their current form, they are not capable of managing ownership boundaries and RRRs associated with underground assets.

The integrated representation of physical and ownership objects could help communicate and identify the spatial location of RRR and ownership boundaries in a real-world context. Examples of 3D integrated data models include the OGC Land and Infrastructure Conceptual Model (LandInfra) used to model information about land and infrastructure facilities [72] and its GML encoding InfraGML [73], the application of LandInfra/InfraGML for BIM-GIS integration (IFC and CityGML) [74], the integration of LADM and CityGML data models [75,76], and the connection of LADM and IFC data models [77]. Existing integrated 3D data models mostly focus on aboveground land administration. Although LandInfra includes physical aspects of underground assets, it also considers ownership elements related to land parcels and buildings. Three-dimensional underground land administration is broader and includes the subdivision, registration, and management of underground assets. However, LandInfra only models the geometry of legal boundaries and cannot distinguish semantic of boundaries [36]. There is a significant research gap in developing a 3D integrated data environment to manage the physical reality and legal extent of underground assets.

Another main technical challenge of the ULA domain is insufficiently precise and detailed underground data such as vertical information (height and depth), spatial information, and legal ownership information [20]. A lack of accurate and detailed information makes it challenging to manage underground assets $[60,78]$. In the majority of cases, the necessary data for creating a 3D geometry of an underground object and a 3D object representing legal space are not provided [79]. The required data acquisition for underground spaces is much more challenging than that for aboveground spaces [20]. A few studies have worked on acquiring underground data for 3D cadastral systems [20,61,80-84]. However, the integrity of cadastral systems depends on data quality and needs valid cadastral data [35,85], and special data acquisition and validation methods are needed for underground assets because they are not or are rarely visible, especially in city centres where many underground assets are located $[10,61]$.

Two-dimensional visualisation approaches also have some limitations in representing underground assets. It is impossible to identify and visualise utilities located at the same location but in different depths in 2D [20], which leads to visual clutter. Additionally, measuring the length, area, and volume of a 3D property is difficult in 2D [26]. Therefore, the $3 \mathrm{D}$ visualisation of underground assets has been considered in recent decades. 
Some studies have developed and tested different applications for visualising 3D underground assets [12,14,56,82,86-97]. However, there are still limitations in platforms used for efficiently visualising underground assets. Visualising underground assets has mostly concentrated on physical elements. There has been a lack of research in underground asset visualisation methods and associated RRRs [26,53].

For disseminating underground data, some services such as calling services and open data portals are helpful, but they provide 2D physical data that are often incomplete and inaccurate [98]. In 3D underground land administration, three-dimensional physical and legal data of different underground assets are needed.

In summation, there are inadequate technical guidelines to cover 3D underground land administration data acquisition, mapping, and modelling [18]. Studies on the technical aspects of ULA have also been limited in focus to, e.g., data modelling, acquisition, and visualisation. Some stages such as underground cadastral data validation, analysis and query, dissemination, and data integration have been less investigated.

The technical implementation of 3D underground land administration requires addressing a series of important research questions. These questions are:

1. What are the 3D data requirements for underground land administration?

2. What 3D data capturing methods can be used for sourcing 3D underground data?

3. What 3D data validation rules for checking the geometrical and semantical completeness and correctness of 3D underground data need to be developed?

4. What would be the potential 3D data format for the storage of 3D underground digital models?

5. What are the technical challenges associated with adopting current 3D data models in underground land administration?

6. How can current 3D data models be enhanced/adopted to support a fully integrated 3D data environment for underground land administration?

7. What are the users' requirements for the 3D visualisation of underground physical and legal data?

8. What kind of analyses and queries are needed for a 3D ULA system to meet the requirements of different use cases?

\section{Proposed Framework for 3D ULA and Future Research Directions}

A holistic framework can provide crucial components of ULA. It is necessary for different jurisdictions to develop roadmaps for 3D ULA, which could also help to identify research gaps in this domain. Figure 7 presents the proposed framework in terms of the technical, legal, and institutional aspects. Addressing these aspects is necessary to transform the existing fragmented and isolated 2D underground land administration practices into a fully 3D digital environment.

In terms of the legal aspects, developing a legislative framework plays foundational role to ensure that the $3 \mathrm{D}$ digital registration of underground assets is recognised and supported by the law. The investigation of existing acts and regulations is vital to specify the required development/changes to legalise 3D digital environments for underground land administration. Regulations need to fully support 3D models for subdividing and registering underground assets and associated 3D RRRs.

The institutional setting of underground land administration is complex, and many important stakeholders can be involved in different processes and workflows over the lifecycle of underground assets. These stakeholders include land registry, city councils, referral authorities (utility authorities, transportation authorities, etc.), land surveyors, planners, developers (builders), owners, and architects. Identifying the involved parties and relevant stakeholders and their roles, responsibilities, tasks, and requirements (needs and interests) is very important in an effective ULA system. Several parties have assets and benefit in underground spaces. They have specific and sometime different policies, processes, and security and data sharing concerns that can affect fully integrated 3D ULA systems. Therefore, establishing collaboration strategies and developing an institutional 
framework and workflow to register whole underground assets in a single model could be complex and thus requires comprehensive research studies in this area. A roadmap is required to identify the critical steps towards transforming the existing systems into a fully integrated 3D digital ULA system.

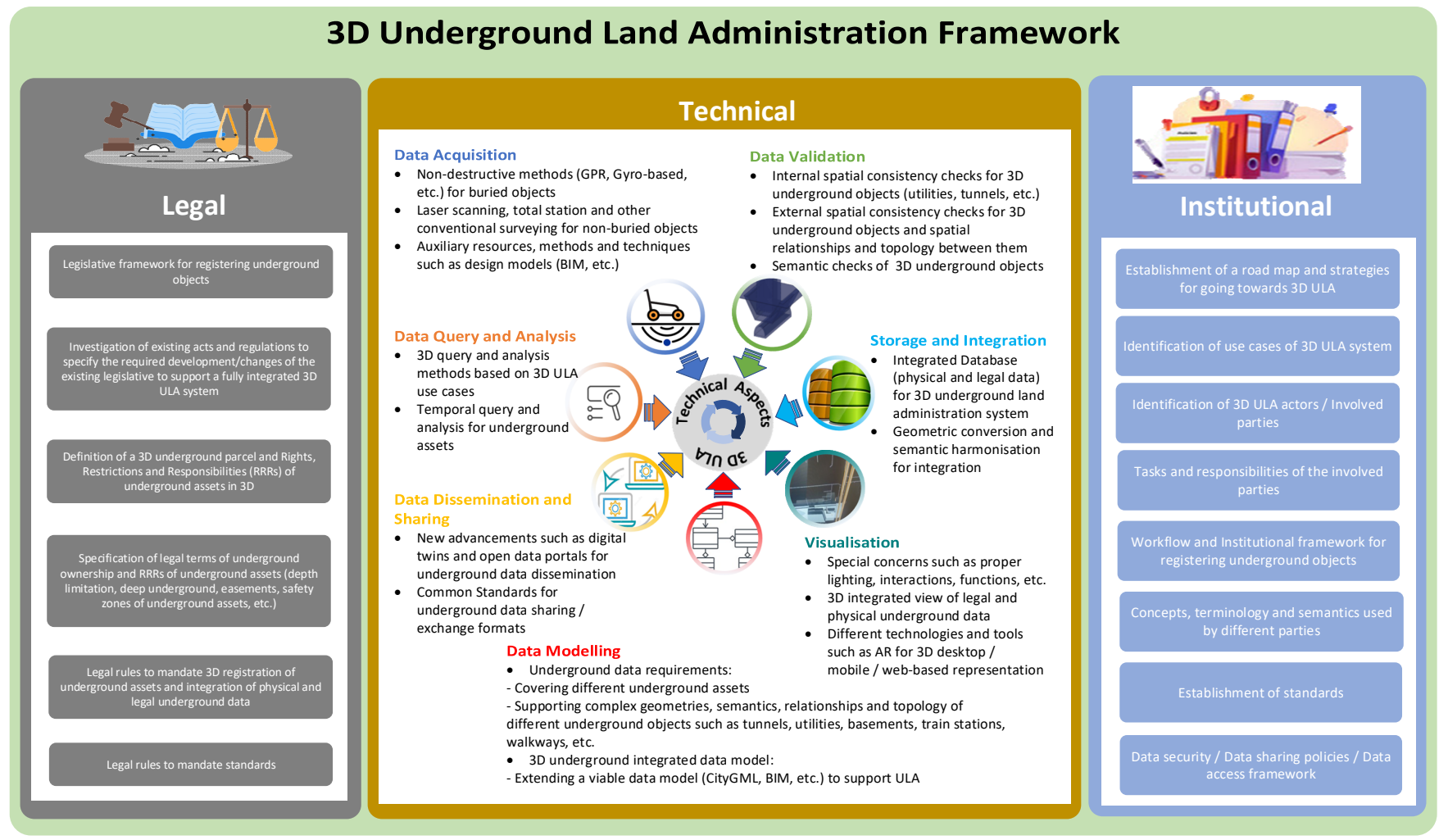

Figure 7. A technical framework as the basis for developing a new ULA system.

Identifying the use cases of a 3D ULA system is necessary to elicit requirements and recognize stakeholders of 3D ULA. Some studies have identified use cases of underground asset management systems [99-101], but they merely focused on the physical location of underground assets. It is necessary to consider ownership RRRs to develop more comprehensive use cases for 3D ULA and support a range of important applications such as underground land registration, planning, designing and constructing assets, subsurface utility management, excavation, and digital twins.

In terms of the technical aspects, several steps such as underground data acquisition, validation, modelling, visualisation, and query and analysis need to be considered to move towards 3D ULA.

Most underground assets such as utility networks are buried. They can be acquired by non-destructive mapping technologies such as ground-penetrating radar (GPR). Laser scanning techniques, total station use, and conventional surveying can also be employed for mapping inside an underground construction. In general, each technology has its own advantages and limitations, and the choice of technique depends on the application [61]. On the other hand, auxiliary resources, methods, and techniques such as BIM models can be used. The combination of methods may also be an applicable solution.

The collected data need to be evaluated to guarantee that the various cadastral data can be trusted and encompass enough detail to define the spatial and legal extents of ownership [35]. Different validation rules should be developed to check the geometrical and semantical completeness and correctness of 3D ULA physical and legal data. Asghari, Kalantari [35] discussed three aspects of checking the validity of cadastral data: non-spatial regulatory checks, internal spatial consistency checks to ensure that single cadastral objects are defined correctly, and external spatial consistency checks to ensure that the objects 
are correctly positioned in relation to a datum and other cadastral objects [35]. Validation rules need to be extended to support underground assets such as tunnels and utilities and their ownership. On the other hand, examining the semantic aspects of underground assets requires a new set of validation rules that should check the 3D underground object's geometry to ensure the internal consistency of underground objects (e.g., closeness of underground lots) and the external consistency of objects (e.g., overlapping geometries between a tunnel and legal space of parcels). Semantic and regulatory checks of 3D underground objects (such as depth limitation) also need to be considered.

A 3D data model with comprehensive geometry and semantics needs to be developed to enable the management of underground assets. It should support different use cases related to ULA and be extended to cover all underground assets. To develop a new 3D underground data model, it is necessary to consider the cadastral data requirements in each jurisdiction. In general, legal boundaries are defined by both surveyed and physical boundaries. Surveyed boundaries can be defined using two approaches: the relative (bearings and distances of boundaries) (e.g., Australia [102]) and geospatial coordinates of boundary points (e.g., Singapore [103]). Legal coordinated cadastres use geodetic coordinates to define boundary corner locations [103]. The defined relative legal boundaries should not change over time and should be consistent with those defined in survey plans or digital cadastral models. The Earth's tectonic plates are continuously moving, and this movement is fast in some jurisdictions such as Australia. In this situation, although legal boundaries cannot change, their coordinates are able to change [104]. Therefore, these jurisdictions (e.g., Australia) use distance and bearing to define the legal boundaries of ownership spaces. Regarding legal boundaries defined by physical structures, there is also some uncertainty about whether a physical structure is stable or has moved and been disturbed due to its lack of stability [103].

Based on these considerations and requirements, a new 3D data model could be developed, but this is a time-consuming and costly approach. It is also possible to define interlinkage between physical 3D data models and legal 3D data models for a 3D integrated underground data model for those jurisdictions where both surveyed and physical boundaries are used. However, interlinkage through external connections has some challenges such as geometric conversion and semantic harmonisation [64]. Alternatively, available extension mechanisms in existing 3D data models can be used. For example, for those jurisdictions where physical structures are not used to define any legal boundaries, extending and customising a purely legal model such as LADM based on the requirements, current practices, and legislation in the context of that particular jurisdiction could be investigated. Alternatively, some data models such as CityGML and BIM that cover physical aspects have recently been developed. These data models contain a broad set of entities for the spatial and semantic aspects of underground environments. Therefore, in jurisdictions where both surveyed and physical boundaries are used, extending the mentioned physical data models with cadastral information to support a fully integrated 3D ULA requires further investigation.

It should be noted that though physical information is not included in the survey plans used for underground land registration in some jurisdictions, it can facilitate the communication of underground ownership spaces. In addition, this information is required for a holistic 3D underground data model in different use cases. In other words, combining legal and physical data within a common 3D environment can support the broader functions and applications of ULA $[65,105]$. Finally, connectivity between physical structures (e.g., utility networks) and legal objects (e.g., easements associated with utility networks) enables the checking of the spatial and semantic consistency between them [31].

Query and spatial analysis cannot be executed if a digital cadastral database does not support all 3D data [26]. Therefore, spatial databases need to be established and standardised to register and manage 3D subsurface assets [18]. Databases can be used to store and manage both spatial and non-spatial ULA data. A spatial database management sys- 
tem should support importing, spatial indexing, manipulating, and restructuring various spatial data types (e.g., point, line, polygon, solid, and point cloud) [25].

Data integration refers to accessing multiple data sources and combining data [106], and it is important for underground space because subsurface asset data (physical data) are often held on multiple platforms with no central repository [60]. On the other hand, data in different organisations can have incompatibilities (e.g., different names, attributes, coordinate systems, spatial dimensions (2D/3D), geometric representations, semantics, and the quality and format of data) [25]. Additionally, organisations use different ways to record an object in the registration of underground assets such as utility networks. For example, a holder may register a long object (e.g., a water pipeline) in one file, resulting in one registration number while another holder registers every segment in a separate file, resulting in hundreds of registration numbers [10]. Therefore, it is necessary to consider geometric conversion and semantic harmonisation for integration. In order to integrate and harmonise different data, standardised formats and protocols for data storage should be used [25].

It is necessary to identify the requirements for the 3D visualisation of the physical and legal data of underground assets. For example, special concerns such as proper lighting, interactions, and functions are required to efficiently visualise underground assets [107]. Different technologies and tools such as AR can be employed to visualise underground assets in an integrated 3D environment. 3D desktop, mobile, or web-based representation of physical and legal data need to be considered based on the established requirements.

Some advancements such as digital twins and open data portals can be used to disseminate underground 3D data. Web services can be used for data dissemination. The use of a web-based 3D ULA system can be beneficial and needs further investigation. Data sharing across stakeholders also has several benefits in the land administration domain; however, standards need to be developed for sharing data, and standardised approaches and exchange formats are needed to address interoperability issues [25].

Standards are necessary for different steps of ULA such as data integration, visualisation, and sharing. Some standards for 3D are currently being developed, but they been been so for particular purposes [25]. There is no international standard that has been broadly applied to model subsurface features in a 3D environment [20,101]. It is necessary to study standards for ULA in depth. Additionally, legal rules are required to mandate the standards.

The 3D query and analysis of ULA can be very complex and goes beyond 3D visualisation. It is necessary to identify the analyses and queries required for 3D ULA and then develop methods for them. Additionally, the fourth dimension (time) is essential for different underground assets, especially utilities, and needs to be added to such analyses and queries.

\section{Summary and Conclusions}

This work identified critical challenges and future directions in terms of legal, institutional, and technical aspects to upgrade ULA from current 2D fragmented and isolated representations into fully 3D digital environments. A new framework was proposed for 3D underground physical and legal data management. The proposed framework provides critical components that are fundamental to implementing a 3D-enabled system for ULA.

According to the framework, several activities should be considered when planning, implementing, and managing a ULA system. While some activities may be conducted for both aboveground and underground environments, some activities should be specifically undertaken for implementing 3D ULA systems. From a technical point of view, there are some common tools, methods, and models for both aboveground and underground spaces, including 3D data acquisition methods (e.g., laser scanning), the 3D data validation of aboveground and underground RRRs, and the development of a 3D digital cadastral database. However, there are some significant differences: 
1. The 3D data acquisition of buried objects may be differently achieved than the methods used for none-buried objects.

2. Specific 3D geometric and semantic validation methods are needed for underground assets such as utilities and tunnels.

3. There are $3 \mathrm{D}$ visualisation requirements that are specific to underground spaces.

4. The development of a comprehensive 3D data model considering a wide range of legal and physical data elements associated with different underground assets (e.g., tunnels, utilities, private basements, shopping malls, train stations, walkways, heritages, and mines) is required.

5. Implementing specific 3D data analysis and query methods to support ULA use cases is required.

Regarding institutional aspects, some use cases such as land registration may be similar to aboveground cases. However, other use cases (such as the excavation; utility management; and planning, design, and construction of an underground tunnel) are specific to underground areas. They require in depth investigation to identify the requirements of ULA systems. Some parties, such as utility authorities, play critical roles in 3D ULA. In underground space, several private and public stakeholders have benefits and interests. This creates complex institutional arrangements for ULA. Each of these parties have their own administrative framework, processes, policies, semantics, etc. Therefore, the establishment of a holistic administrative framework for 3D ULA to define the roles and tasks of these parties and collaboration strategies is crucial.

Underground space legislation may also be different than aboveground legislation in some cases. In the current practice, depth limitations are mainly used to define the underground ownership of land parcels, though they are typically defined as textual annotations and their legal definitions are often unclear. Regulations should be modified to specify the spatial extent of depth limitations in a 3D environment. It is also necessary to investigate all RRRs associated with the underground environment to support 3D ULA. For example, easement and public land (crown) legislation are very important when planning, constructing, and managing underground built assets.

In summation, to transform the existing 2D ULA system into a 3D digital ULA system, it is necessary to identify the required development and modifications of the existing legislative and institutional frameworks. In addition, there are several knowledge gaps in technical aspects, including 3D underground data validation, an integrated 3D data model extending to cover different subsurface assets, analyses and queries for different ULA use cases, integrated database for 3D ULA systems, underground visualisation requirements, and standards for underground data sharing. Therefore, new investigations that consider the requirements of different use cases in the real world are required to fully address the legal, institutional, and technical aspects of ULA.

Author Contributions: Conceptualization, B.S.; methodology, B.S.; software, B.S.; validation, B.S.; formal analysis, B.S.; investigation, B.S.; resources, B.S.; data curation, B.S.; writing—original draft preparation, B.S.; writing-review and editing, B.S., A.R., B.A. and M.K.; visualization, B.S.; supervision, A.R., B.A. and M.K.; project administration, A.R.; funding acquisition, A.R. All authors have read and agreed to the published version of the manuscript.

Funding: This research was funded by the Australian Research Council, grant number LP160100292.

Acknowledgments: The authors acknowledge the support of project partners. The authors also emphasise that the views expressed in this paper are the authors' alone.

Conflicts of Interest: The authors declare no conflict of interest.

\section{References}

1. Cai, F.; Ji, J.M.; Jiang, Z.Q.; Mu, Z.R.; Wu, X.; Zheng, W.J.; Zhou, W.X.; Tu, S.T.; Qian, X. Engineering Fronts in 2018. Engineering 2018, 4, 748-753. [CrossRef]

2. Von der Tann, L.; Sterling, R.; Zhou, Y.; Metje, N. Systems approaches to urban underground space planning and management-A review. Undergr. Space 2020, 5, 144-166. [CrossRef] 
3. AADBYDS. Association of Australian Dial before You Dig. Services 20 Year History. 2019. Available online: https://www.1100 .com.au/association-of-australian-dial-before-you-dig-services-20-year-history/ (accessed on 12 July 2020).

4. Peng, F.L.; Qiao, Y.K.; Sabri, S.; Atazadeh, B.; Rajabifard, A. A collaborative approach for urban underground space development toward sustainable development goals: Critical dimensions and future directions. Front. Struct. Civ. Eng. 2021, 15, 20-45. [CrossRef]

5. Rajabifard, A.; Atazadeh, B.; Kalantari, M. BIM and Urban Land Administration; CRC Press: Boca Raton, FL, USA, 2019.

6. Oxford Business Group. Ground Rules: Land Acquisition Issues Emerge on the Route of the Klang Valley Mass Transit System. 2020. Available online: https:/ / oxfordbusinessgroup.com/analysis/ground-rules-land-acquisition-issues-emerge-route-klangvalley-mass-transit-system (accessed on 25 October 2020).

7. DELWP. Common Terms in Land Titles; 2020. Available online: https://www.propertyandlandtitles.vic.gov.au/land-titles/ common-terms (accessed on 5 October 2020).

8. Ploeger, H.D.; Stoter, J.E. Cadastral registration of cross-boundary infrastructure objects. In Proceedings of the FIG Working Week 2004: The Olympic Spirit in Surveying, Athens, Greece, 22-27 May 2004.

9. Stoter, J.E. 3D Cadastre; Delft University of Technology: Delft, The Netherlands, 2004.

10. Pouliot, J.; Girard, P. 3D Cadastre: With or without Subsurface Utility Network? In Proceedings of the 5th International FIG 3D Cadastre Workshop, Athens, Greece, 18-20 October 2016.

11. Land Use Victoria. In Subdivision Plan; Department of Environment, Land, Water \& Planning Melbourne: East Melbourne, Australia, 2020.

12. Olde Scholtenhuis, L.L.; den Duijn, X.; Zlatanova, S. Representing geographical uncertainties of utility location data in 3D. Autom. Constr. 2018, 96, 483-493. [CrossRef]

13. Karataş, K.; Bıyık, C.; Demir, O. The Underground Cadastre and Its Implementations in Turkey. In Proceedings of the Shaping the Change XXIII FIG Congress, Munich, Germany, 8-13 October 2006.

14. Den Duijn, X. A 3D Data Modeling Approach for Integrated Management of below and above Ground Utility Network Features; Delft University of Technology: Delft, The Netherlands, 2018.

15. Bobylev, N. Underground space as an urban indicator: Measuring use of subsurface. Tunn. Undergr. Space Technol. 2016, 55, 40-51. [CrossRef]

16. Janečka, K.; Bobíková, D. Registering the underground objects in the 3D cadastre: A case study of wine cellar located in the vineyard area Tokaj. Acta Montan. Slovaca 2018, 23, 260-270.

17. Kim, S.; Heo, J. Development of 3D underground cadastral data model in Korea: Based on land administration domain model. Land Use Policy 2017, 60, 123-138. [CrossRef]

18. Kim, S.; Heo, J. Registration of 3D underground parcel in Korean cadastral system. Cities 2019, 89, 105-119. [CrossRef]

19. Matuk, O. Conception of Registration of Underground Spatial Structures in Modern 3D Cadastral System. Geomat. Environ. Eng. 2019, 13, 47-60. [CrossRef]

20. Yan, J.; Jaw, S.W.; Soon, K.H.; Wieser, A.; Schrotter, G. Towards an Underground Utilities 3D Data Model for Land Administration. Remote Sens. 2019, 11, 1957. [CrossRef]

21. United Nations/Economic Commission for Europe. Land Administration Guidelines: With Special Reference to Countries in Transition; United Nations/Economic Commission for Europe: Geneva, Switzerland, 1996.

22. Indrajit, A.; Jaya, V.E.; van Loenen, B.; Lemmen, C.; van Oosterom, P.; Ploeger, H.; Theodore, R. The Role of the Revised Land Administration Domain Model and Spatial Data Infrastructure in Improving Ease of Doing Business in Indonesia. In Proceedings of the 2020 World Bank Conference On Land And Poverty, Washington, DC, USA, 16-20 March 2020.

23. Williamson, I.; Enemark, S.; Wallace, J.; Rajabifard, A. Land Administration for Sustainable Development; ESRI Press Academic: Redlands, CA, USA, 2010.

24. ICSM. Cadastre 2034-Powering Land and Real Property: Cadastral Reform and Innovation for Australia-A National Strategy; Intergovernmental Committee on Surveying and Mapping (ICSM): Canberra, Australia, 2013.

25. Kalogianni, E.; van Oosterom, P.; Dimopoulou, E.; Lemmen, C. 3D Land Administration: A review and a future vision in the context of the spatial development lifecycle. ISPRS Int. J. Geo-Inf. 2020, 9, 107. [CrossRef]

26. Aien, A.; Rajabifard, A.; Kalantari, M.; Williamson, I. Aspects of 3D cadastre: A case study in Victoria. In Proceedings of the FIG Working Week 2011, Marrakech, Morocco, 18-22 May 2011.

27. Paulsson, J.; Paasch, J.M. 3D property research from a legal perspective. Comput. Environ. Urban Syst. 2013, 40, 7-13. [CrossRef]

28. Lokrantz, H. 2012. Available online: https://www.slideshare.net/SGU_Sverige/02-geoarena-citybananhanna (accessed on 2 May 2020).

29. Leksono, B.E.; Ristiawan, A.; Sadikin, H.; Meyke, L. The Underground Space Use Right Registration with the Approach of 3 Dimensional Cadastre Concept. In Cadastre: Geo-Information Innovations in Land Administration; Springer: Cham, Switzerland, 2017; pp. 121-136.

30. Zaini, F.; Hussin, K.; Raid, M. Legal considerations for urban underground space development in Malaysia. Undergr. Space 2017, 2, 234-245. [CrossRef]

31. Döner, F.; Thompson, R.; Stoter, J.; Lemmen, C.; Ploeger, H.; van Oosterom, P.; Zlatanova, S. 4D cadastres: First analysis of legal, organizational, and technical impact-With a case study on utility networks. Land Use Policy 2010, 27, 1068-1081. [CrossRef]

32. Paasch, J.M.; Paulsson, J. 3D Property Research from a Legal Perspective Revisited. Land 2021, 10, 494. [CrossRef] 
33. Daems, J. KLIP as a Response to the OGC Underground RFI; Informatie Vlaanderen: Brussel, Belgium, 2017.

34. Aien, A. 3D Cadastral Data Modelling; University of Melbourne: Melbourne, Australia, 2013.

35. Asghari, A.; Kalantari, M.; Rajabifard, A. A structured framework for 3D cadastral data validation-A case study for Victoria, Australia. Land Use Policy 2020, 98, 104359. [CrossRef]

36. Atazadeh, B. Building Information Modelling for Urban Land Administration; University of Melbourne: Melbourne, Australia, 2017.

37. Van Oosterom, P.; Erba, D.A.; Aien, A.; Grant, D.; Kalantari, M.; Karki, S.; Shojaei, D.; Thompson, R.; Muggenhuber, G.; Navratil, G.; et al. Best Practices 3D Cadastres: Extended Version; International Federation of Surveyors (FIG): Copenhagen, Denmark, 2018.

38. Atazadeh, B.; Rajabifard, A.; Zhang, Y.; Barzegar, M. Querying 3D cadastral information from BIM models. ISPRS Int. J. Geo-Inf. 2019, 8, 329. [CrossRef]

39. Kalogianni, E.; Dimopoulou, E.; Thompson, R.J.; Lemmen, C.; Ying, S.; van Oosterom, P. Development of 3D spatial profiles to support the full lifecycle of 3D objects. Land Use Policy 2020, 98, 104177. [CrossRef]

40. Arancibia, G.; Philips, W.; Janes, A. The 3D Cadastre for underground infrastructure: A challenged approach from Professional Surveyors Canada. In Proceedings of the FIG Congress 2018, Istanbul, Turkey, 6-11 May 2018.

41. Sandberg, H. Three-dimensional partition and registration of subsurface land space. Isr. Law. Rev. 2003, 37, 119. [CrossRef]

42. Barker, M. Legal and administrative issues in underground space use: A preliminary survey of ITA member nations. Tunn. Undergr. Space Technol. 1991, 6, 191-209. [CrossRef]

43. Pouliot, J.; Girard, P. Subsurface Utility Network Registration and the Publication of Real Rights: Pending for a Full 3D Cadastre. In Proceedings of the FIG Working Week, Christchurch, New Zealand, 2-6 May 2016.

44. Kitsakis, D.; Paasch, J.M.; Paulsson, J.; Navratil, G.; Vučić, N.; Karabin, M.; El-Mekawy, M.; Koeva, M.; Janecka, K.; Erba, D.; et al. Best Practices 3D Cadastres_Chapter 1. Legal foundations; International Federation of Surveyors (FIG): Copenhagen, Denmark, 2018.

45. Wenjun, Z.; Jun, Y.; Xingde, K. Integrated Administration of Urban Underground Space in China: Laws E Regulations, Present E Future; Research Publishing: Singapore, 2013.

46. Darin, G. Legal Operations from Below: The Compulsory Purchase of Subsoil Rights for Underground Tunnels; St Cross College: Oxford, UK, 2019.

47. Tsvetkov, O.; Vasileva, E.; Kulakov, K. Features of cadastral registration of real estate objects using 3D technologies. In Proceedings of the E3S Web of Conferences, Rostov-on-Don, Russia, 20-23 October 2020; EDP Sciences: Les Ulis, France, 2020. [CrossRef]

48. Thomas, W.A. Ownership of Subterranean Space. Undergr. Space 1979, 3, 155-163.

49. Zhang, Z.; Tang, W.; Gong, J. Property rights of urban underground space in China: A public good perspective. Land Use Policy 2017, 65, 224-237. [CrossRef]

50. $\mathrm{Xu}, \mathrm{S}$. Research on current legislation for urban underground space in China. In Proceedings of the International Conference on Pipelines and Trenchless Technology 2014 (ICPTT), Xiamen, China, 13-15 November 2014; pp. 1-12.

51. Zaini, F.; Hussin, K.; Jamalludin, N.A.; Zakaria, S.R.A. The principle of depth for underground land development: A review. J. Teknol. 2015, 75. [CrossRef]

52. Yan, J.; Soon, K.H.; Jaw, S.W.; Schrotter, G. A LADM-based 3D Underground Utility Data Model: A Case Study of Singapore. In Proceedings of the 8th International FIG workshop on the Land Administration Domain Model, Kuala Lumpur, Malaysia, 1-3 October 2019.

53. Aien, A.; Rajabifard, A.; Kalantari, M.; Williamson, I. Review and assessment of current cadastral data models for 3D cadastral applications. In Advances in 3D Geoinformation; Springer: Cham, Switzerland, 2017; pp. 423-442.

54. Knoth, L.; Atazadeh, B.; Rajabifard, A. Developing a new framework based on solid models for 3D cadastres. Land Use Policy 2020, 92, 104480. [CrossRef]

55. Karabin, M.; Kitsakis, D.; Koeva, M.; Navratil, G.; Paasch, J.M.; Paulsson, J.; Vučić, N.; Janečk, K.; Lisec, A. Layer approach to ownership in 3D cadastre: A subway case. In Proceedings of the 6th International FIG 3D Cadastre Workshop, Delft, The Netherlands, 2-4 October 2018; pp. 111-136.

56. Pouliot, J.; Bordin, P.; Cuissard, R. Cadastral mapping for underground networks: A preliminary analysis of user needs. In Proceedings of the International Cartographic Conference, Rio de Janeiro, Brazil, 23-28 August 2015.

57. Atazadeh, B.; Kalantari, M.; Rajabifard, A.; Ho, S. Modelling building ownership boundaries within BIM environment: A case study in Victoria, Australia. Comput. Environ. Urban. Syst. 2017, 61, 24-38. [CrossRef]

58. Libbis, S. Subdivisions Victoria: The Ultimate Guide; Hybrid Publishers: Onitsha, Nigeria, 2018.

59. Melbourne Water Corporation. Sewerage Network Main Pipelines; Melbourne Water Corporation: Melbourne, Austrlia, 2020.

60. Geovation. Deep Dig, Underground Assets Challenge; Geovation: London, UK, 2016.

61. Yan, J.; Jaw, S.W.; Van Son, R.; Soon, K.H.; Schrotter, G. Three-dimensional data modelling for underground utility network mapping. Int. Arch. Photogramm. Remote Sens. Spat. Inf. Sci. 2018, 42, 711-715. [CrossRef]

62. Yan, J.; Jaw, S.W.; Soon, K.H.; Schrotter, G. The ladm-based 3d underground utility mapping: Case study in Singapore. In Proceedings of the International Archives of the Photogrammetry, Remote Sensing and Spatial Information Sciences, Singapore, 24-27 September 2019. [CrossRef]

63. Karabin, M.; Kitsakis, D.; Koeva, M.; Navratil, G.; Paasch, J.M.; Paulsson, J.; Vučić, N.; Janečka, K.; Lisec, A. Layer approach to ownership in 3D cadastre in the case of underground tunnels. Land Use Policy 2020, 98, 104464. [CrossRef]

64. Atazadeh, B.; Kalantari, M.; Rajabifard, A.; Ho, S.; Champion, T. Extending a BIM-based data model to support 3D digital management of complex ownership spaces. Int. J. Geogr. Inf. Sci. 2017, 31, 499-522. [CrossRef] 
65. Aien, A.; Kalantari, M.; Rajabifard, A.; Williamson, I.; Wallace, J. Towards integration of 3D legal and physical objects in cadastral data models. Land Use Policy 2013, 35, 140-154. [CrossRef]

66. Den Duijn, X.; Agugiaro, G.; Zlatanova, S. Modelling below-and above-ground utility network features with the CityGML Utility Network ADE: Experiences from Rotterdam. In Proceedings of the 3rd International Conference on Smart Data and Smart Cities, Delft, The Netherlands, 4-5 October 2018.

67. Lemmen, C.; van Oosterom, P.; Bennett, R. The land administration domain model. Land Use Policy 2015, 49, 535-545. [CrossRef]

68. Silva, W.D.O.; Carneiro, A.F.T. Subsurface Utility Network Cadastre Proposal, Based on Ladm (ISO/FDIS 19152). Bol. Ciênc. Geod. 2020, 26. [CrossRef]

69. Yan, J.; van Son, R.; Soon, K.H. From underground utility survey to land administration an underground utility 3D data model. Land Use Policy 2021, 102, 105267. [CrossRef]

70. Gröger, G.; Kolbe, T.H.; Nagel, C.; Häfele, K.H. OGC City Geography Markup Language (CityGML) Encoding Standard; Open Geospatial Consortium: Wayland, MA, USA, 2012.

71. ISO. Industry Foundation Classes (IFC) for Data Sharing in the Construction and Facility Management Industries; International Organization for Standardization (ISO): Geneva, Switzerland, 2013.

72. Scarponcini, P. OGC ${ }^{\circledR}$ Land and Infrastructure Conceptual Model. Standard (LandInfra); Open Geospatial Consortium: Wayland, MA, USA, 2016; Version 1.0.

73. OGC. OGC LandInfra/InfraGML. 2021. Available online: https://www.ogc.org/standards/infragml (accessed on 27 September 2021).

74. Kumar, K.; Labetski, A.; Ohori, K.A.; Ledoux, H.; Stoter, J. The LandInfra standard and its role in solving the BIM-GIS quagmire. Open Geospat. Data Softw. Stand. 2019, 4, 1-16. [CrossRef]

75. Góźdź, K.; Pachelski, W.; van Oosterom, P.; Coors, V. The possibilities of using CityGML for 3D representation of buildings in the cadastre. In Proceedings of the 4th International Workshop on 3D Cadastres, Dubai, United Arab Emirates, 9-11 November 2014.

76. Li, L.; Wu, J.; Zhu, H.; Duan, X.; Luo, F. 3D modeling of the ownership structure of condominium units. Comput. Environ. Urban. Syst. 2016, 59, 50-63. [CrossRef]

77. Atazadeh, B.; Kalantari, M. Connecting LADM and IFC Standards-Pathways towards an Integrated Legal-Physical Model. In Proceedings of the 7th International FIG Workshop on the Land Administration Domain Model, Zagreb, Croatia, 12-13 April 2018.

78. Bitenc, M.; Dahlberg, K.; Doner, F.; van Goor, B.; Lin, K.; Yin, Y.; Yuan, X.; Zlatanova, S. Utility registration: Slovenia, China, Sweden and Turkey. GISt Rep. 2008, 49, 48.

79. Višnjevac, N.; Mihajlović, R.; Šoškić, M.; Cvijetinović, Ž.; Marošan, S.; Bajat, B. Developing Serbian 3D Cadastre System-Challenges and Directions. In Proceedings of the 6th International FIG 3D Cadastre Workshop, Delft, The Netherlands, 2-4 October 2018; FIG (International Federation of Surveyors): Delft, The Netherlands, 2018.

80. Mazlan, H.; Jaw, S.; Maged, M. Subsurface utility mapping for underground cadastral infrastructure. In Proceedings of the 31st Asian Conference on Remote Sensing, Hanoi, Vietnam, 1-5 November 2010.

81. Bieda, A.; Bydłosz, J.; Warchoł, A.; Balawejder, M. Historical Underground Structures as 3D Cadastral Objects. Remote Sens. 2020, 12, 1547. [CrossRef]

82. Kim, S.; Kim, J.; Jung, J.; Heo, J. Development of a 3D underground cadastral system with indoor mapping for as-built BIM: The case study of gangnam subway station in korea. Sensors 2015, 15, 30870-30893. [CrossRef]

83. Hu, J.; Zheng, Z.R.; You, Y.; Shi, F.X. Discussion Cadastral Survey of the Underground Space of the 3D Cadastre. Mod. Surv. Mapp. 2012, 18. [CrossRef]

84. Ustavich, G.A.; Salnikova, P.P.; Salnikov, V.G.; Soboleva, E.L. Development of the technological scheme of surveying works for cadastral registration of underground parkings. Vestn. SSUGT 2018, 3, 28-31. [CrossRef]

85. Asghari, A.; Kalantari, M.; Rajabifard, A. Advances in techniques to formulate the watertight concept for cadastre. Trans. GIS 2021, 25, 213-237. [CrossRef]

86. Döner, F.; Thompson, R.; Stoter, J.; Lemmen, C.; Ploeger, H.; van Oosterom, P.; Zlatanova, S. Solutions for 4D cadastre-with a case study on utility networks. Int. J. Geogr. Inf. Sci. 2011, 25, 1173-1189. [CrossRef]

87. Jeong, D.H.; Jang, B.B.; Lee, J.Y.; Hong, S.I.; Van Oosterom PJ, M.; de Zeeuw, K.; Stoter, A.; Lemmen, C.; Zevenbergen, J. Initial design of an LADM-based 3D Cadastre-Case study from Korea. In Proceedings of the 3rd International FIG Workshop on 3D Cadastres: Developments and practices, Shenzhen, China, 25-26 October 2012; International Federation of Surveyors (FIG): Copenhagen, Denmark, 2012.

88. Liu, R.; Issa, R. 3D visualization of sub-surface pipelines in connection with the building utilities: Integrating GIS and BIM for facility management. In Proceedings of the International Conference on Computing in Civil Engineering, Clearwater Beach, FL, USA, 17-20 June 2012; pp. 341-348. [CrossRef]

89. Fenais, A. Developing an Augmented Reality Solution for Mapping Underground Infrastructure. Ph.D. Thesis, Arizona State University, Tempe, AZ, USA, 2020.

90. Andrianesi, D.; Dimopoulou, E.A. Integrated Bim-Gis Platform for Representing and Visualizing 3d Cadastral Data. ISPRS Ann. Photogramm. Remote Sens. Spat. Inf. Sci. 2020, 6, 3-11. [CrossRef] 
91. Ortega, S.; Wendel, J.; Santana, J.M.; Murshed, S.M.; Boates, I.; Trujillo, A.; Nichersu, A.; Suárez, J.P. Making the Invisible Visible-Strategies for Visualizing Underground Infrastructures in Immersive Environments. ISPRS Int. J. Geo-Inf. $2019,8,152$. [CrossRef]

92. Guo, R.; Li, L.; Ying, S.; Luo, P.; He, B.; Jiang, R. Developing a 3D cadastre for the administration of urban land use: A case study of Shenzhen, China. Comput. Environ. Urban. Syst. 2013, 40, 46-55. [CrossRef]

93. Becker, T.; Nagel, C.; Kolbe, T.H. Semantic 3D modeling of multi-utility networks in cities for analysis and 3D visualization. In Progress and New Trends in 3D Geoinformation Sciences; Springer: Berlin/Heidelberg, Germany, 2013; pp. 41-62.

94. Guerrero, J.; Zlatanova, S.; Meijers, B. 3D visualisation of underground pipelines: Best strategy for 3D scene creation. In Proceedings of the 8th 3DGeoInfo Conference \& WG II/2 Workshop, Istanbul, Turkey, 27-29 November 2013. ISPRS Archives Volume II-2/W1, ISPRS.

95. Balogun, A.-L.; Matori, A.-N.; Lawal, D.U. Geovisualization of sub-surface pipelines: A 3D approach. Mod. Appl. Sci. 2011, 5, 158. [CrossRef]

96. Pouliot, J.; Ellul, C.; Hubert, F.; Wang, C.; Rajabifard, A.; Kalantari, M. Visualization and new opportunities. In Best 3D Cadastres: Extended Version; International Federation of Surveyors (FIG): Copenhagen, Denmark, 2018.

97. Chen, Q.; Liu, G.; Ma, X.; Yao, Z.; Tian, Y.; Wang, H. A virtual globe-based integration and visualization framework for aboveground and underground 3D spatial objects. Earth Sci. Inform. 2018, 11, 591-603. [CrossRef]

98. Davidson, N. 3D BIM Underground Assets; Engineering for Public Works (EPW): Queensland, Australia, 2016.

99. Lieberman, J. Model for Underground Data Definition and Integration (MUDDI) Engineering Report; Open Geospatial Consortium: Wayland, MA, USA, 2019.

100. Lieberman, J.; Roensdorf, C. Modular Approach to 3D Representation of Underground Infrastructure in the Model for Underground Data Definition and Integration (MUDDI). Int. Arch. Photogramm. Remote Sens. Spat. Inf. Sci. 2020, $44,75-81$. [CrossRef]

101. Lieberman, J.; Ryan, A. OGC Underground Infrastructure Concept Study Engineering Report; OGC Engineering Report; Open Geospatial Consortium: Wayland, MA, USA, 2017.

102. LandVictoria. ePlan Handbook: Version 2.2; Department of Environment, Land, Water \& Planning Melbourne: Melbourne, Australia, 2019.

103. Brown, C.A. The Millimeter Legal Coordinated Cadaster; The University of Maine: Orono, ME, USA, 2011.

104. ICSM. GDA Frequently Asked Questions. 2021. Available online: https://www.icsm.gov.au/datum/gda-frequently-askedquestions (accessed on 1 October 2021).

105. Shojaei, D.; Kalantari, M.; Bishop, I.D.; Rajabifard, A.; Aien, A. Visualization requirements for 3D cadastral systems. Comput. Environ. Urban. Syst. 2013, 41, 39-54. [CrossRef]

106. Plale, B.; Kouper, I. The centrality of data: Data lifecycle and data pipelines. In Data Analytics for Intelligent Transportation Systems; Elsevier: Amsterdam, The Netherlands, 2017; pp. 91-111.

107. Shojaei, D. 3D Cadastral Visualisation: Understanding Users' Requirements. Ph.D. Thesis, University of Melbourne, Melbourne, Australia, 2014. 